\section{A) Check for updates}

Cite this: Polym. Chem., 2017, 8 , 2773

Received 17th January 2017 Accepted 5th April 2017

DOI: 10.1039/c7py00091j

rsc.li/polymers

\title{
Triple-stimuli-responsive ferrocene-containing homopolymers by RAFT polymerization $\uparrow$
}

\author{
Xue Jiang, $\star^{a}$ Ruru Li, $\$^{a}, b$ Chun Feng, ${ }^{\text {a }}$ Guolin Lu and Xiaoyu Huang (ID*a,b
}

\begin{abstract}
Well-defined ferrocene-containing homopolymers were synthesized by RAFT homopolymerization of an acrylate monomer bearing a ferrocene $(\mathrm{Fc})$ unit and an $\mathrm{N}, \mathrm{N}$-diethylamino ethyl (DEAE) group, i.e. 2-(3-(N(2-(diethylamino)ethyl)-acrylamido)propanoyloxy)ethyl ferrocenecarboxylate (Fc-DEAE-AM). As an ideal redox-responsive group, hydrophobic $\mathrm{Fc}$ can be easily oxidized into hydrophilic $\mathrm{Fc}^{+}$by certain oxidants, providing tremendous opportunities to produce various Fc-containing redox-responsive materials. On the other hand, the $\mathrm{pH} / \mathrm{CO}_{2}$-responsive reversible nature of the DEAE group makes it possible to construct a smart system to adapt to the complex environment in practical application. The stimuli-responsive aggregation behavior of the well-defined poly(Fc-DEAE-AM) homopolymer is examined by the combination of a fluorescent probe, UV/vis transmittance, zeta potential, transmission electron microscopy (TEM), and dynamic light scattering (DLS). In fact, due to the redox and $\mathrm{pH} / \mathrm{CO}_{2}$-responsive character provided by the Fc and DEAE groups, the poly(Fc-DEAE-AM) homopolymer exhibits distinct phase transition in aqueous solution. In addition, such a homopolymer could form typical spherical particles in acid aqueous solution, and the redox agent could lead to changes in the size and morphology of the aggregates. Thus, we provide a new and efficient way to prepare triple-stimuli-responsive Fc-containing homopolymers, which might be used as interesting building block for the fabrication of multiple stimuli-responsive functional materials.
\end{abstract}

\section{Introduction}

Polymeric stimuli-responsive materials have attracted significant attention in many areas of chemistry, as these intelligent polymers with sharp polarity change upon stimulation show impressive potential for a variety of interesting applications. ${ }^{1-6}$ Most related research focused on smart polymer-based materials using just a single stimulus. However, the practical applications of stimuli-responsive polymers are usually in complex environments. In some cases, multiple stimuli are particularly appealing for the fabrication of smart materials with much more precise and sensitive stimuli-responsiveness. ${ }^{7,8}$

As redox reactions are widely and constantly present in the body metabolism, redox-responsive polymers have recently gained considerable attention because of their potential in

\footnotetext{
${ }^{a}$ Key Laboratory of Synthetic and Self-Assembly Chemistry for Organic Functional Molecules, Shanghai Institute of Organic Chemistry, Chinese Academy of Sciences, 345 Lingling Road, Shanghai 200032, People's Republic of China.

E-mail: cfeng@mail.sioc.ac.cn, xyhuang@mail.sioc.ac.cn; Fax: +86-21-64166128; Tel: +86-21-54925606, +86-21-54925310

${ }^{b}$ School of Physical Science \& Technology, ShanghaiTech University, 100 Haike Road, Shanghai 201210, People's Republic of China

$\dagger$ Electronic supplementary information (ESI) available. See DOI: 10.1039/ c7py00091j

$\$$ Both authors contributed equally to this work.
}

controllable transport and release in physiological environments. ${ }^{9-20}$ As is well-known, redox-responsive polymers mainly contain sulfur, ${ }^{9}$ selenium, ${ }^{10,11}$ ferrocene $(\mathrm{Fc}),{ }^{12-23}$ and other functionalities. Compared with sulfur and selenium, the hydrophobic Fc group can be quickly oxidized to yield the hydrophilic ferrocenium cation $\left(\mathrm{Fc}^{+}\right)$, which can be reversibly recovered by a reductant. The reversible change in hydrophilicity with a rapid response is realized by only a gain and loss of electrons without a change in molecular structure, which is especially of interest to scientists for developing new redoxresponsive polymers. ${ }^{12-14}$ For example, Zhang et al. have discovered a kind of multi-compartment nanoassembly via a poly(2-(dimethylamino)ethyl methacrylate)-block-poly(benzyl methacrylate)-block-poly(4-vinylbenzyl ferrocenecarboxylate) (PDMAEMA- $b$-PBzMA- $b$-PVFC) triblock copolymer prepared by seeded RAFT polymerization. ${ }^{14}$ The multi-compartment vesicles could be expected to be smart hosts to load and release guests, as the membrane pores could be reversibly on-off switched through redox triggering. Gallei et al. synthesized a diblock copolymer consisting of poly(vinylferrocene) and poly $(\mathrm{N}, \mathrm{N}$-diethylacrylamide) via a combination of anionic and RAFT polymerization, which showed both thermo- and redoxresponsive character. ${ }^{20}$ Wurm et al. prepared poly(ferrocenyl glycidyl ether)-co-poly(ethylene glycol) (PfcGE-co-PEG) random copolymers by anionic ring-opening polymerization of a ferro- 
cene-containing epoxide monomer of ferrocenyl glycidyl ether with ethylene oxide, and this kind of copolymer also exhibited both thermo- and redox-responsiveness. ${ }^{22}$ After introducing amine functionalities into PfcGE-co-PEG by a post-polymerization functionalization strategy, the obtained copolymer was able to demonstrate temperature, $\mathrm{pH}$ and redox triple-stimuliresponsiveness both in solution and on the surface. ${ }^{23}$ Although chain extension and post-polymerization modification strategies could be employed for the preparation of Fcbased copolymers with multiple stimuli-responsiveness, the tedious purification process of the chain extension strategy and the ill-defined distribution of functional groups along the backbone of the final polymers prepared by the post-polymerization approach would be the obstacles for preparation of well-defined Fc-based multiple stimuli-responsive polymers.

Recently, our group developed an efficient synthetic route for the preparation of multi-responsive homopolymers functionalized with different reactive groups. ${ }^{24-26}$ Motivated by the excellent redox-responsive abilities attributed to Fc-containing polymers, herein, we attempted to incorporate redox responsiveness into a new dual-responsive homopolymer so as to realize the triple-trigger-controlled dynamic association and dissociation of the polymer chain. Owing to the key step of the aza-Michael addition reaction, the Fc unit and the $N, N$-diethylamino ethyl (DEAE) group with both $\mathrm{pH}$ and $\mathrm{CO}_{2}$ responsiveness ${ }^{27-31}$ could be easily incorporated into one single monomer (Scheme 1), providing a new acrylate monomer, $\quad 2-(3-(N-(2-$ (diethylamino)ethyl)acrylamido)propanoyloxy)ethyl ferrocenecarboxylate (Fc-DEAE-AM). Subsequently, RAFT homopolymerization of Fc-DEAE-AM was utilized to afford the target well-defined homopolymer with controlled molecular weight and narrow molecular weight distribution. It was observed that variation in acid/alkali reagents, bubbling $\mathrm{N}_{2} / \mathrm{CO}_{2}$, and redox reagents could all induce reversible phase transition in aqueous solution. To the best of our knowledge, $\mathrm{pH} / \mathrm{CO}_{2}$ - and redox-responsive homopolymers have not been reported yet, which is crucial to exploit new trigger modes as close to physiological conditions as possible. The presented triple-stimuli-responsive system has many advantages such as facile sample preparation and the possibility to produce multifunctional materials, which may bring great opportunities to enlarge the potential applications of this class of homopolymers.

\section{Experimental}

\section{Materials}

2,2'-Azobis(isobutyronitrile) (AIBN, Aldrich, 98\%) was recrystallized twice from anhydrous ethanol. Toluene and dichloromethane were dried over $\mathrm{CaH}_{2}$ and distilled under reduced pressure prior to use. Triethylamine $\left(\mathrm{Et}_{3} \mathrm{~N}\right.$, Aldrich, $\left.99.5 \%\right)$ was dried over $\mathrm{KOH}$ and distilled over $\mathrm{CaH}_{2}$ under $\mathrm{N}_{2}$ prior to use. $N$-Phenyl-1-naphthylamine (PNA, Alfa Aesar, 97\%) was purified by recrystallization in ethanol three times. Ferrocenecarboxylic acid (TCI, 98\%), oxalyl chloride (Sinopharm, 98\%), N,N-diethylethylenediamine (J\&K, 99\%), 2-hydroxyethyl acrylate (HEA, Aldrich, 97\%), and acryloyl chloride (Aldrich, 97\%) were used as received. 4-Cyano-4-(dodecylsulfanylthiocarbonylsulfanyl)pentanoic acid was synthesized according to previous literature. ${ }^{32}$

\section{Measurements}

All ${ }^{1} \mathrm{H}$ and ${ }^{13} \mathrm{C}$ NMR analyses were performed on a JEOL resonance ECZ 400S $(400 \mathrm{MHz})$ in $\mathrm{CDCl}_{3}$ and $\mathrm{D}_{2} \mathrm{O}$, tetramethylsilicone $\left({ }^{1} \mathrm{H}\right.$ NMR $)$ and $\mathrm{CDCl}_{3}\left({ }^{13} \mathrm{C}\right.$ NMR $)$ were used as internal standards. FT-IR spectra were recorded on a Nicolet AVATAR-360 spectrophotometer with a $4 \mathrm{~cm}^{-1}$ resolution. Electrospray ionization mass spectrometry (ESI-MS) and high resolution mass spectrometry (HR-MS) were performed by using an Agilent LC/MSD SL system and a Thermo Fisher Scientific LTQ FT Ultra system, respectively. Relative molecular
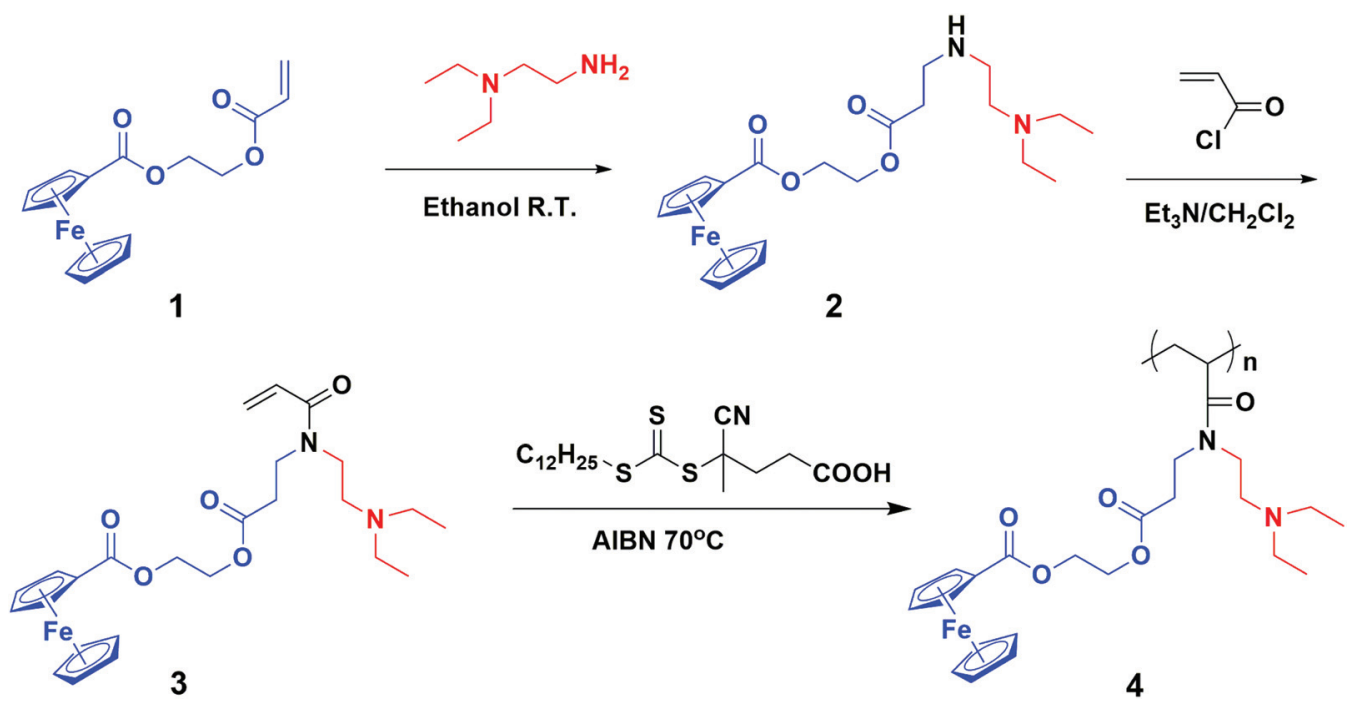

Scheme 1 Synthetic route of poly(2-(3-(N-(2-(diethylamino)ethyl)acrylamido)-propanoyloxy)ethyl ferrocenecarboxylate) homopolymer. 
weights and molecular weight distributions were measured by a conventional gel permeation chromatography (GPC) system equipped with a Waters 515 Isocratic HPLC pump, a Waters 2414 refractive index detector, and a set of Waters Styragel columns (HR3 (500-30 000), HR4 (5000-600 000), and HR5 (50 000-4 000000$), 7.8 \times 300 \mathrm{~mm}$, particle size: $5 \mu \mathrm{m}$ ). GPC measurements were carried out at $35{ }^{\circ} \mathrm{C}$ using THF as the eluent with a flow rate of $1.0 \mathrm{~mL} \mathrm{~min}^{-1}$. The system was calibrated with linear poly(methyl methacrylate) standards. The phase transition of the homopolymer was measured by UV/vis spectroscopy using a Hitachi U-2910 spectrophotometer. Transmission electron spectroscopy (TEM) images were obtained by a JEOL JEM-1230 instrument operated at $80 \mathrm{kV}$. Zeta-potential was determined in $\mathrm{KCl}$ aqueous media $(5.0 \mathrm{mM})$ at $25{ }^{\circ} \mathrm{C}$ by a Malvern Nano-ZS90 Zetasizer. The hydrodynamic diameter $\left(D_{\mathrm{h}}\right)$ was measured using dynamic light scattering (DLS), with a Malvern Nano-ZS90 Zetasizer. The samples were allowed to equilibrate for $2 \mathrm{~min}$ at $25{ }^{\circ} \mathrm{C}$ prior to measurement. Steady-state fluorescence spectra were measured at $20{ }^{\circ} \mathrm{C}$ on a Hitachi $\mathrm{F}-2700$ fluorescence spectrophotometer with a bandwidth of $5 \mathrm{~nm}$ for excitation and emission, and the emission intensity at $418 \mathrm{~nm}$ was recorded to determine the critical aggregation concentration (CAC), where the excitation wavelength $\left(\lambda_{\text {ex }}\right)$ was $340 \mathrm{~nm}$.

\section{Preparation of ferrocenecarbonyl chloride}

Oxalyl chloride $(50 \mathrm{~mL})$ was added dropwise to a solution of ferrocene carboxylic acid $(23.0 \mathrm{~g}, 0.1 \mathrm{~mol})$ in anhydrous $\mathrm{CH}_{2} \mathrm{Cl}_{2}(300 \mathrm{~mL})$ at $0{ }^{\circ} \mathrm{C}$. The reaction mixture was stirred at $0^{\circ} \mathrm{C}$ for $30 \mathrm{~min}$ and then at room temperature for another $6 \mathrm{~h}$. Both the solvent and excess oxalyl chloride were removed by distillation under reduced pressure. The resulting mixture was triturated with hot $n$-hexane followed by filtration, and the filtrate was concentrated to give $20.6 \mathrm{~g}$ of red crystal with a yield of $82.9 \%$.

\section{Preparation of 2-acryloxyethyl ferrocenecarboxylate}

Ferrocenecarbonyl chloride (20.6 g, $82.9 \mathrm{mmol}$ ) was dissolved in $250 \mathrm{~mL}$ of anhydrous $\mathrm{CH}_{2} \mathrm{Cl}_{2}$, and the solution was cooled to $0{ }^{\circ} \mathrm{C}$ by using an ice bath. After mixing HEA (11.55 g, $99.48 \mathrm{mmol}), \mathrm{Et}_{3} \mathrm{~N}(23.1 \mathrm{~mL}, 165.8 \mathrm{mmol})$, and anhydrous $\mathrm{CH}_{2} \mathrm{Cl}_{2}(50 \mathrm{~mL})$ in the constant pressure liquid funnel, the mixture was added dropwise to the stirring solution within $10 \mathrm{~min}$. The reactor was slowly warmed up to room temperature. After $12 \mathrm{~h}$, the precipitated salt was removed by filtration. The filtrate was evaporated under reduced pressure, and the residue was purified by flash column chromatography on a silica gel column eluting with EtOAc/hexane ( $\mathrm{v}: \mathrm{v}=1: 8)$, to give $25.3 \mathrm{~g}(93.0 \%)$ of orange crystal, 2-acryloxyethyl ferrocenecarboxylate 1. ${ }^{1} \mathrm{H} \mathrm{NMR}\left(\mathrm{CDCl}_{3}\right): \delta(\mathrm{ppm}): 4.19\left(5 \mathrm{H}, \mathrm{C}_{5} H_{5}\right)$, $4.40\left(2 \mathrm{H}, \mathrm{CCH}_{2} \mathrm{C}_{2} \mathrm{H}_{2}\right), 4.47\left(4 \mathrm{H}, \mathrm{OCH}_{2} \mathrm{CH}_{2} \mathrm{O}\right), 4.81(2 \mathrm{H}$, $\left.\mathrm{CCH}_{2} \mathrm{C}_{2} \mathrm{H}_{2}\right), 5.86,6.17,6.50\left(3 \mathrm{H}, \mathrm{CH}=\mathrm{CH}_{2}\right) .{ }^{13} \mathrm{C} \mathrm{NMR}\left(\mathrm{CDCl}_{3}\right)$ : $\delta$ (ppm): $61.87\left(\mathrm{OCH}_{2} \mathrm{CH}_{2} \mathrm{O}\right), 62.47\left(\mathrm{OCH}_{2} \mathrm{CH}_{2} \mathrm{O}\right), 69.82\left(C_{5} \mathrm{H}_{5}\right)$, $70.22, \quad 70.53, \quad 71.48 \quad\left(C_{5} \mathrm{H}_{4}\right), \quad 128.00 \quad\left(\mathrm{CH}=\mathrm{CH}_{2}\right), \quad 131.45$ $\left(\mathrm{CH}=\mathrm{CH}_{2}\right), 165.91\left(\mathrm{OCOCH}=\mathrm{CH}_{2}\right), 171.52\left(\mathrm{OCOC}_{5} \mathrm{H}_{4}\right)$. FT-IR: $\nu\left(\mathrm{cm}^{-1}\right): 3090,2954,2924,2852,1712,1635,1458,1407,1376$,
1272, 1185, 1132, 982, 930, 806, 769, 430, 413. DART-MS: calculated $\mathrm{C}_{16} \mathrm{H}_{16} \mathrm{O}_{4}{ }^{54} \mathrm{Fe}$ for 326.0439; found 326.0437 .

Preparation of 2-(3-(2-(diethylamino)ethylamino)propanoyloxy) ethyl ferrocenecarboxylate

2-Acryloxyethyl ferrocenecarboxylate 1 (20.5 g, $62.5 \mathrm{mmol})$ was dissolved in $300 \mathrm{~mL}$ of anhydrous EtOH. While stirring vigorously, $N, N$-diethylethylenediamine (60 mmol, $6.973 \mathrm{~g}$ ) was added and then the mixture was stirred for $12 \mathrm{~h}$ at ambient temperature. The volatiles were evaporated under reduced pressure, and the residue was purified by flash chromatography on a silica gel column, eluting with EtOAc/hexane $(\mathrm{v}: \mathrm{v}=1: 1$, with $\left.\mathrm{Et}_{3} \mathrm{~N}\right)$, to give $10.4 \mathrm{~g}(37.5 \%)$ of sticky orange liquid, 2-(3-(2(diethylamino)-ethylamino)propanoyloxy)ethyl ferrocenecarboxylate 2. ${ }^{1} \mathrm{H} \mathrm{NMR}\left(\mathrm{CDCl}_{3}\right): \delta(\mathrm{ppm}): 1.00\left(6 \mathrm{H}, \mathrm{N}\left(\mathrm{CH}_{2} \mathrm{CH}_{3}\right)_{2}\right), 2.15$ $(1 \mathrm{H}, \mathrm{NH}), 2.56\left(8 \mathrm{H}, \mathrm{COCH}_{2} \mathrm{CH}_{2}\right.$ and $\left.\mathrm{CH}_{2} \mathrm{~N}\left(\mathrm{CH}_{2} \mathrm{CH}_{3}\right)_{2}\right), 2.68(2 \mathrm{H}$, $\left.\mathrm{NHCH}_{2} \mathrm{CH}_{2} \mathrm{~N}\right), 2.93\left(2 \mathrm{H}, \mathrm{COCH}_{2} \mathrm{CH}_{2} \mathrm{NH}\right), 4.21\left(5 \mathrm{H}, \mathrm{C}_{5} \mathrm{H}_{5}\right), 4.41$ $\left(6 \mathrm{H}, \mathrm{CCH}_{2} \mathrm{C}_{2} \mathrm{H}_{2}, \mathrm{OCH}_{2} \mathrm{CH}_{2} \mathrm{O}\right), 4.81\left(2 \mathrm{H}, \mathrm{CCH}_{2} \mathrm{C}_{2} \mathrm{H}_{2}\right) .{ }^{13} \mathrm{C} \mathrm{NMR}$ $\left(\mathrm{CDCl}_{3}\right): \delta$ (ppm): $11.18\left(\mathrm{~N}\left(\mathrm{CH}_{2} \mathrm{CH}_{3}\right)_{2}\right), 29.67\left(\mathrm{COCH}_{2} \mathrm{CH}_{2} \mathrm{NH}\right)$, $34.11 \quad\left(\mathrm{NHCH}_{2} \mathrm{CH}_{2} \mathrm{~N}\right), \quad 44.84 \quad\left(\mathrm{COCH}_{2} \mathrm{CH}_{2} \mathrm{NH}\right), \quad 46.93$ $\left(\mathrm{N}\left(\mathrm{CH}_{2} \mathrm{CH}_{3}\right)_{2}\right), 71.50\left(\mathrm{NHCH}_{2} \mathrm{CH}_{2} \mathrm{~N}\right), 61.78\left(\mathrm{OCH}_{2} \mathrm{CH}_{2} \mathrm{O}\right), 62.59$ $\left(\mathrm{OCH}_{2} \mathrm{CH}_{2} \mathrm{O}\right), 69.81\left(C_{5} \mathrm{H}_{5}\right), 70.20,70.44,71.50\left(C_{5} \mathrm{H}_{4}\right), 172.39$ $\left(\mathrm{OCOC}_{2} \mathrm{H}_{4}\right), 171.54\left(\mathrm{OCOC}_{5} \mathrm{H}_{4}\right)$. FT-IR: $\nu\left(\mathrm{cm}^{-1}\right)$ : 3320, 3090, 2964, 2926, 2816, 1738, 1717, 1461, 1377, 1276, 1182, 1139, 1063, 1025, 821, 772, 484, 458, 412. DART-MS: calculated $\mathrm{C}_{22} \mathrm{H}_{33} \mathrm{~N}_{2} \mathrm{O}_{4}{ }^{54} \mathrm{Fe}$ for 443.1836; found $443.1827[\mathrm{M}+\mathrm{H}]^{+}$.

\section{Preparation of 2-(3-( $\mathrm{N}$-(2-(diethylamino)ethyl)acrylamido) propanoyloxy)ethyl ferrocenecarboxylate}

2-(3-(2-(Diethylamino)ethylamino)propanoyloxy)ethyl ferrocenecarboxylate $2(8.3 \mathrm{~g}, 18.7 \mathrm{mmol})$ and $\mathrm{Et}_{3} \mathrm{~N}(6.3 \mathrm{~mL}$, $44.8 \mathrm{mmol}$ ) were dissolved in $150 \mathrm{~mL}$ of anhydrous $\mathrm{CH}_{2} \mathrm{Cl}_{2}$. The solution was cooled to $0{ }^{\circ} \mathrm{C}$ followed by addition of acryloyl chloride $(2.0 \mathrm{~g}, 22.4 \mathrm{mmol})$ dropwise within $15 \mathrm{~min}$. The mixture was slowly warmed up to room temperature and stirred at room temperature for $12 \mathrm{~h}$. The volatiles were evaporated under reduced pressure, and the residue was purified by flash chromatography on a silica gel column eluting with EtOAc/hexane $\left(\mathrm{v}: \mathrm{v}=1: 5\right.$, with $\left.\mathrm{Et}_{3} \mathrm{~N}\right)$, to give $3.7 \mathrm{~g}(39.7 \%)$ of sticky orange liquid, 2-(3-( $N$-(2-(diethylamino)ethyl)acrylamido)-propanoyloxy)ethyl ferrocenecarboxylate (Fc-DEAE-AM) 3. ${ }^{1} \mathrm{H}$ NMR $\left(\mathrm{CDCl}_{3}\right): \delta(\mathrm{ppm}): 0.95\left(6 \mathrm{H}, \mathrm{N}\left(\mathrm{CH}_{2} \mathrm{CH}_{3}\right)_{2}\right), 2.51(8 \mathrm{H}$, $\mathrm{COCH}_{2} \mathrm{CH}_{2}$ and $\left.\mathrm{CH}_{2} \mathrm{~N}\left(\mathrm{CH}_{2} \mathrm{CH}_{3}\right)_{2}\right), 3.40\left(2 \mathrm{H}, \mathrm{CONCH}_{2} \mathrm{CH}_{2} \mathrm{~N}\right)$, $3.66\left(2 \mathrm{H}, \mathrm{COCH}_{2} \mathrm{CH}_{2} \mathrm{NCO}\right), 4.13\left(5 \mathrm{H}, \mathrm{C}_{5} H_{5}\right), 4.34(6 \mathrm{H}$, $\left.\mathrm{CCH}_{2} \mathrm{C}_{2} \mathrm{H}_{2}, \mathrm{OCH}_{2} \mathrm{CH}_{2} \mathrm{O}\right), 4.74\left(2 \mathrm{H}, \mathrm{CCH}_{2} \mathrm{C}_{2} \mathrm{H}_{2}\right), 5.61,6.29,6.46$ $\left(3 \mathrm{H}, \quad \mathrm{CH}=\mathrm{CH}_{2}\right) . \quad{ }^{13} \mathrm{C} \quad \mathrm{NMR} \quad\left(\mathrm{CDCl}_{3}\right): \quad \delta \quad(\mathrm{ppm}): \quad 11.92$ $\left(\mathrm{N}\left(\mathrm{CH}_{2} \mathrm{CH}_{3}\right)_{2}\right), 32.62\left(\mathrm{COCH}_{2} \mathrm{CH}_{2} \mathrm{NCO}\right), 34.17\left(\mathrm{CONCH}_{2} \mathrm{CH}_{2} \mathrm{~N}\right)$, $43.57 \quad\left(\mathrm{COCH}_{2} \mathrm{CH}_{2} \mathrm{NCO}\right), \quad 47.39 \quad\left(\mathrm{~N}\left(\mathrm{CH}_{2} \mathrm{CH}_{3}\right)_{2}\right), \quad 52.42$ $\left(\mathrm{CONCH}_{2} \mathrm{CH}_{2} \mathrm{~N}\right), 61.74\left(\mathrm{OCH}_{2} \mathrm{CH}_{2} \mathrm{O}\right), 62.54\left(\mathrm{OCH}_{2} \mathrm{CH}_{2} \mathrm{O}\right), 69.76$ $\left(C_{5} \mathrm{H}_{5}\right), 70.15,70.43,71.42\left(C_{5} \mathrm{H}_{4}\right), 127.52\left(C \mathrm{H}=\mathrm{CH}_{2}\right), 127.89$ $\left(\mathrm{CH}=\mathrm{CH}_{2}\right), \quad 166.33 \quad(\mathrm{NCO}), \quad 170.75 \quad\left(\mathrm{OCOC}_{2} \mathrm{H}_{4}\right), \quad 171.89$ $\left(\mathrm{OCOC}_{5} \mathrm{H}_{4}\right)$. FT-IR: $\nu\left(\mathrm{cm}^{-1}\right): 3090,2962,2926,1737,1716$, 1650, 1613, 1460, 1376, 1274, 1136, 1068, 1025, 822, 794, 772, 438, 421. DART-MS: calculated $\mathrm{C}_{25} \mathrm{H}_{35} \mathrm{~N}_{2} \mathrm{O}_{5}{ }^{54} \mathrm{Fe}$ for 497.1942; found $497.1930[\mathrm{M}+\mathrm{H}]^{+}$. 


\section{RAFT homopolymerization of Fc-DEAE-AM}

In a typical procedure, Fc-DEAE-AM 3 (0.58 g, $1.16 \mathrm{mmol})$, AIBN (2.8 mg, $0.017 \mathrm{mmol})$, and 4-cyano-4-(dodecylsulfanylthiocarbonylsulfanyl)pentanoic acid $(21.0 \mathrm{mg}, 0.052 \mathrm{mmol})$ were first added to a $25 \mathrm{~mL}$ Schlenk flask (flame-dried under vacuum prior to use) sealed with a rubber septum for degassing and kept under $\mathrm{N}_{2}$. Next, anhydrous toluene $(0.6 \mathrm{~mL})$ was charged via a gastight syringe. The flask was degassed by three cycles of freezing-pumping-thawing followed by immersing the flask into an oil bath set at $70{ }^{\circ} \mathrm{C}$. The polymerization lasted $19 \mathrm{~h}$ and it was terminated by placing the flask into liquid $\mathrm{N}_{2}$. The reaction mixture was precipitated into cold $n$-hexane. The crude product was purified by repeated dissolution in THF and precipitation in cold $n$-hexane followed by drying in vacuo overnight to give a yellow oil of poly(FcDEAE-AM) 4a homopolymer. GPC: $M_{\mathrm{n}}=3700 \mathrm{~g} \mathrm{~mol}^{-1}, M_{\mathrm{w}} / M_{\mathrm{n}}$ $=1.21 .{ }^{1} \mathrm{H} \mathrm{NMR}\left(\mathrm{CDCl}_{3}\right): \delta(\mathrm{ppm}): 0.98\left(6 \mathrm{H}, \mathrm{N}\left(\mathrm{CH}_{2} \mathrm{CH}_{3}\right)_{2}\right), 1.26$ $\left(18 \mathrm{H}, \mathrm{CH}_{3} \mathrm{C}_{9} \mathrm{H}_{18} \mathrm{C}_{2} \mathrm{H}_{4}\right), 1.73\left(2 \mathrm{H}, \mathrm{CHCOCH}_{2} \mathrm{CHCO}\right), 2.33(\mathrm{H}$, $\mathrm{CH}_{2} \mathrm{CHCO}$ ), 2.49-2.65 (8H, $\left.\mathrm{COCH}_{2} \mathrm{CH}_{2}, \mathrm{CH}_{2} \mathrm{~N}\left(\mathrm{CH}_{2} \mathrm{CH}_{3}\right)_{2}\right), 3.33$ $\left(2 \mathrm{H}, \mathrm{CONCH}_{2} \mathrm{CH}_{2} \mathrm{~N}\right), 3.59\left(2 \mathrm{H}, \mathrm{COCH}_{2} \mathrm{CH}_{2} \mathrm{CON}\right), 4.19(5 \mathrm{H}$, $\left.\mathrm{C}_{5} \mathrm{H}_{5}\right), 4.39\left(6 \mathrm{H}, \quad \mathrm{CCH}_{2} \mathrm{C}_{2} \mathrm{H}_{2}, \quad \mathrm{OCH}_{2} \mathrm{CH}_{2} \mathrm{O}\right), 4.80 \quad(2 \mathrm{H}$, $\left.\mathrm{CCH}_{2} \mathrm{C}_{2} \mathrm{H}_{2}\right)$. FT-IR: $\nu\left(\mathrm{cm}^{-1}\right): 3090,2962,2926,1740,1716$, $1641,1460,1377,1275,1138,1060,1020,825,773,486,459$.

\section{Micellar morphology}

A THF solution of a poly(Fc-DEAE-AM) 4 homopolymer (10.0 $\mathrm{mg} \mathrm{mL}^{-1}$ ) was added dropwise to acidic water under vigorous stirring and bubbling of $\mathrm{N}_{2}$ until the concentration of the homopolymer reached $0.5 \mathrm{mg} \mathrm{mL} \mathrm{mL}^{-1}$. THF was evaporated by moderate stirring overnight at room temperature. For TEM studies, $5 \mu \mathrm{L}$ of micelle solution was deposited on to an electron microscopy copper grid coated with carbon film, and the water was evaporated at room temperature.

\section{Titration experiment}

A $50 \mathrm{~mL}$ three-neck round-bottom flask equipped with Thermo Scientific $^{\mathrm{TM}}$ Orion $^{\mathrm{TM}}$ ROSS Ultra ${ }^{\mathrm{TM}}$ Refillable $\mathrm{pH} / \mathrm{ATC}$ Triode ${ }^{\mathrm{TM}}$ Combination Electrodes and a Lei-Ci DJS-1C Conductance Electrode was used to conduct the potentiometric titration. $20 \mathrm{~mL}$ of poly(Fc-DEAE-AM) 4 homopolymer $\left(2.0 \mathrm{mg} \mathrm{mL}^{-1}\right)$ in aqueous salt solution $([\mathrm{NaCl}]=10 \mathrm{mM}, \mathrm{pH}=2.84)$ was titrated by standard $\mathrm{NaOH}$ solution $(1.0 \mathrm{M})$ under constant stirring and bubbling of $\mathrm{N}_{2}$.

\section{Transmittance experiment}

A poly(Fc-DEAE-AM) $\mathbf{4}$ homopolymer was uniformly dispersed in re-distilled water ultrasonically until the concentration of the homopolymer reached $2.0 \mathrm{mg} \mathrm{mL}{ }^{-1}$. The gas-based transmittance changes of the aqueous solution were measured by a Hitachi U-2910 spectrophotometer at a constant wavelength of $800 \mathrm{~nm}$.

\section{Determination of critical aggregation concentration}

PNA was used as a fluorescent probe to measure the critical aggregation concentration (CAC) of a poly(Fc-DEAE-AM) 4 homopolymer in aqueous media. An acetone solution of PNA $([\mathrm{PNA}]=2 \mathrm{mM})$ was added to a large amount of water until the concentration of PNA reached $0.002 \mathrm{mM}$. The solutions for fluorescence measurement were obtained by adding different amounts of THF solutions of poly(Fc-DEAE-AM) 4 homopolymer $\left(1,0.1,0.01,0.001\right.$, or $\left.0.0001 \mathrm{mg} \mathrm{mL}^{-1}\right)$ to water containing PNA $([\mathrm{PNA}]=0.002 \mathrm{mM})$. THF was evaporated by constant stirring and bubbling of $\mathrm{N}_{2}$ overnight at room temperature. The solution was sealed in closed vials before measurement to avoid the influence of $\mathrm{CO}_{2}$ in the air.

\section{Results and discussion}

\section{Design and synthesis of Fc-DEAE-AM trifunctional acrylate monomers}

Given the well-studied redox-responsive property of ferrocene $\mathrm{e}^{12-23}$ and the $\mathrm{pH} / \mathrm{CO}_{2}$-responsive behavior of PDEAEMA, ${ }^{27-31}$ we attempted to incorporate the redox-responsive $\mathrm{Fc}$ unit and the $\mathrm{pH} / \mathrm{CO}_{2}$-sensitive DEAE group into a single monomer, and utilize RAFT polymerization to construct triple-stimuli-responsive homopolymers. The key in the preparation of the target monomer is to incorporate a polymerizable group, ferrocene unit, and DEAE group within a single monomer. Our group has developed an effective strategy to connect two different groups and an acrylamide group. ${ }^{24-26}$ Inspired by our previous results, we used a similar strategy in the present work. We employed the aza-Michael reaction as a key way to produce the secondary amine target intermediate which can be utilized in a further reaction to afford a polymerizable acrylamide.

The 2-acryloxyethyl ferrocenecarboxylate (AEFC) 1 precursor was first prepared using commercially available ferrocenecarboxylic acid, oxalyl chloride, and 2-hydroxyethyl acrylate as starting materials (Scheme $\mathrm{S} 1 \dagger$ ). Fig. $\mathrm{S} 1 \mathrm{~A}$ and $\mathrm{S} 1 \mathrm{~B} \uparrow$ show the ${ }^{1} \mathrm{H}$ and ${ }^{13} \mathrm{C}$ NMR spectra of the AEFC 1 intermediate, exhibiting the expected proton resonance signals of the target compound. The key intermediate of 2-(3-(2-(diethylamino)ethylamino)propanoyloxy)ethyl ferrocenecarboxylate (Fc-DEAE) 2 was then prepared through aza-Michael addition reaction using AEFC 1 and $N, N$-diethylethylenediamine. ${ }^{1} \mathrm{H}$ (Fig. S2A $\dagger$ ) and ${ }^{13} \mathrm{C}$ (Fig. S2B广) NMR spectra of Fc-DEAE 2 confirmed the chemical structure of the target intermediate. Subsequently, Fc-DEAE 2 was treated with acryloyl chloride to afford the target Fc-DEAE-AM 3 monomer. The Fc-DEAE-AM 3 monomer was characterized by ${ }^{1} \mathrm{H}$ NMR, ${ }^{13} \mathrm{C}$ NMR, FT-IR, and MS. Fig. 1A shows the ${ }^{1} \mathrm{H}$ NMR spectrum of the monomer, which displays the typical proton resonance signals of the double bond at 6.52, 6.28, and 5.61 ppm (peaks "a", "b", and "c"), the Fc moiety at 4.75, 4.34, and 4.14 ppm (peaks "l", "m”, and "n"), and the DEAE group at 0.95 ppm (peak "g"). The ${ }^{13} \mathrm{C}$ NMR spectrum shown in Fig. 1B demonstrates the anticipated carbon resonance signals of carbonyl (peaks "m”, “j”, and “c”) and double bond (peaks "a" and "b"). The structure of the FcDEAE-AM 3 monomer is also confirmed by FT-IR spectroscopy (Fig. S3†). In addition, the ESI-MS (Fig. S4†) and HR-MS 


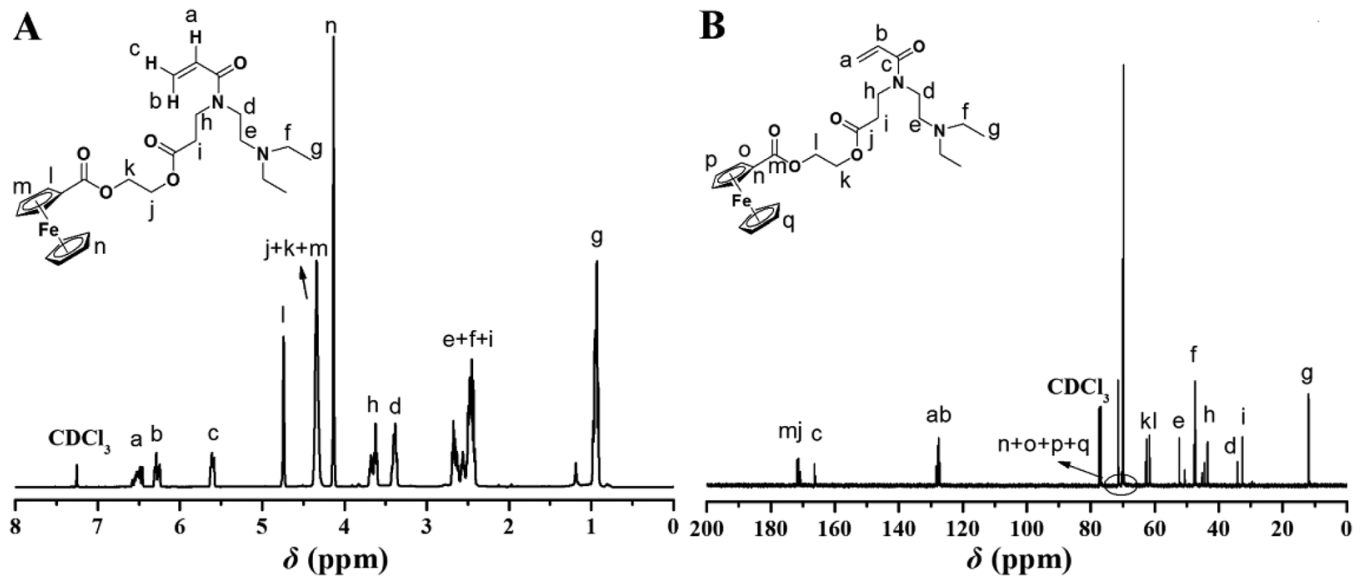

Fig. $1{ }^{1} \mathrm{H}(\mathrm{A})$ and ${ }^{13} \mathrm{C}$ (B) NMR spectra of FC-DEAE-AM 3 monomer in $\mathrm{CDCl}_{3}$.

(497.1930, Fig. S5†) results are in good agreement with the theoretical value $\left(\mathrm{C}_{25} \mathrm{H}_{35} \mathrm{~N}_{2} \mathrm{O}_{5}{ }^{54} \mathrm{Fe}^{+}, 497.1942\right)$. All these results clearly confirm the structure of the target monomer 3 .

\section{Synthesis of poly(Fc-DEAE-AM) homopolymers}

RAFT polymerization ${ }^{32-37}$ is one of the most powerful and versatile reversible-deactivation radical polymerization (RDRP) processes, which enables precise control over molecular weight and molecular weight distribution. RAFT polymerization can be conducted under mild reaction conditions and is tolerant of most functional groups. In particular, RAFT polymerization of the acrylate monomer has been extensively investigated, and 4-cyano-4-(dodecylsulfanylthiocarbonylsulfanyl)-pentanoic acid (CDSTSP) has been frequently selected as the chain transfer agent (CTA) in recent decades. ${ }^{32}$ Considering the good solubility of the Fc moiety, toluene was employed as the solvent for RAFT polymerization of the FcDEAE-AM 3 monomer. Two well-defined poly(Fc-DEAE-AM) 4 homopolymers with narrow molecular weight distributions $\left(M_{\mathrm{w}} / M_{\mathrm{n}} \leq 1.22\right)$ were synthesized by varying the feeding ratio of Fc-DEAE-AM 3 monomer to CDSTSP as listed in Table 1.

The chemical structure of the poly(Fc-DEAE-AM) 4 homopolymer was examined using ${ }^{1} \mathrm{H}$ NMR and FT-IR. A typical ${ }^{1} \mathrm{H}$ NMR spectrum (Fig. 2A) shows the disappearance of double bond peaks and the continuing of the signals originating from the Fc moiety (peak "a", "b", and "c") and the DEAE group (peak "k"). The RAFT mechanism was evidenced by the minor peak "l" located at $1.26 \mathrm{ppm}$ corresponding to the protons of the $-\mathrm{C}_{12} \mathrm{H}_{25}$ moiety in CDSTSP. These observations distinctly illustrated the structure of the obtained poly(Fc-DEAE-AM) 4 homopolymer. Moreover, based on the integration area ratio of peak "a" to peak "l", the absolute molecular weight of the poly (Fc-DEAE-AM) 4 homopolymer could be estimated using the following equation, in which $S_{\mathrm{a}}$ and $S_{1}$ are the integration area of peak "a" and "l", respectively, and $M_{\text {monomer }}$ and 403.67 are the molecular weights of the Fc-DEAE-AM 3 monomer and CDSTSP, respectively. Indeed, it can be seen from Table 1 that $M_{\mathrm{n}, \mathrm{NMR}}$ is very close to the theoretical value $\left(M_{\mathrm{n}, \mathrm{theo}}\right)$, which indicates a good control over molecular weight via RAFT polymerization.

$$
M_{\mathrm{n}, \mathrm{NMR}}=9\left(S_{\mathrm{a}} / S_{\mathrm{l}}\right) M_{\text {monomer }}+403.67
$$

The FT-IR spectrum of the poly(Fc-DEAE-AM) 4 homopolymer is shown in Fig. 2B. The stretching vibrations of $\mathrm{C}-\mathrm{H}$ in the ferrocene groups, $\mathrm{C}-\mathrm{H}$ in-plane, and $\mathrm{C}-\mathrm{H}$ bending vibrations appear at $3090 \mathrm{~cm}^{-1}, 1020-1060 \mathrm{~cm}^{-1}$, and $773-825 \mathrm{~cm}^{-1}$, respectively. The significant peak at $486 \mathrm{~cm}^{-1}$ is attributed to the Fe-Cp stretching mode and the stretching vibrations of the ester and amide groups appear at $1716-1740 \mathrm{~cm}^{-1}$ and $1641 \mathrm{~cm}^{-1}$, respectively. All these results clearly confirm the chemical properties of the poly(FcDEAE-AM) 4 homopolymer.

The polymerization kinetics is further investigated and the linear dependence of $\ln \left([\mathrm{M}]_{\mathrm{o}} /[\mathrm{M}]_{t}\right)$ on the time and molecular

Table 1 Synthesis of poly(Fc-DEAE-AM) homopolymer by RAFT polymerization ${ }^{a}$

\begin{tabular}{lllllll}
\hline Entry & {$[3]:[\mathrm{CTA}]$} & Time (h) & Conv. $^{b}(\%)$ & $M_{\mathrm{n}, \text { theo }}{ }^{c}\left(\mathrm{~g} \mathrm{~mol}^{-1}\right)$ & $M_{\mathrm{n}, \mathrm{NMR}}{ }^{b}\left(\mathrm{~g} \mathrm{~mol}^{-1}\right)$ & $M_{\mathrm{n}, \mathrm{GPC}^{d}\left(\mathrm{~g} \mathrm{~mol}^{-1}\right)} M_{\mathrm{w}} / M_{\mathrm{n}}{ }^{d}$ \\
\hline 4a & $20: 1$ & 19 & 57.0 & 6100 & 6900 & 3700 \\
4b & $35: 1$ & 24 & 57.3 & 10400 & 10200 & 5300
\end{tabular}

${ }_{d}^{a}[\mathrm{AIBN}]:[\mathrm{CTA}]=1: 3$, solvent $:$ toluene, polymerization temperature: $80{ }^{\circ} \mathrm{C} .{ }^{b}$ Obtained from ${ }^{1} \mathrm{H} \mathrm{NMR} .{ }^{c} M_{\mathrm{n}, \text { theo }}=M_{\mathrm{n}, 3} \times([3]:[\mathrm{CTA}]) \times \mathrm{Conv} .+M_{\mathrm{n}, \mathrm{CTA}}$. ${ }^{d}$ Measured by GPC in THF at $35^{\circ} \mathrm{C}$. 
A

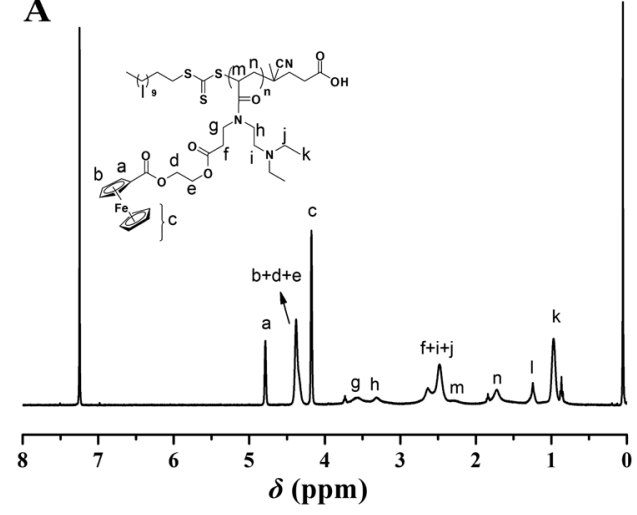

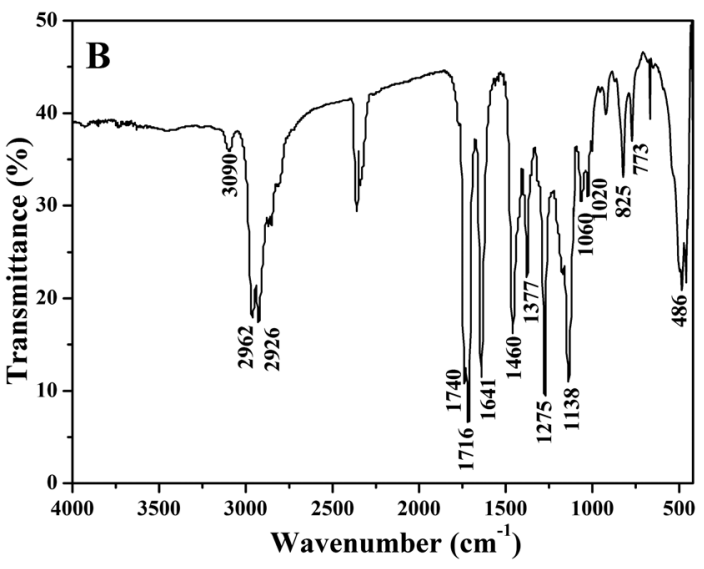

Fig. $2{ }^{1} \mathrm{H}$ NMR (A) and FT-IR (B) spectra of poly(Fc-DEAE-AM) 4 homopolymer.

weight on the monomer conversion are observed in Fig. S6A and $\mathrm{S} 6 \mathrm{~B}, \dagger$ respectively. These observations reflect the "living/ controlled" nature of the RAFT polymerization of the FcDEAE-AM 3 monomer.

\section{$\mathrm{pH} / \mathrm{CO}_{2}$-Responsive behavior of poly(Fc-DEAE-AM) in aqueous media}

Although PDEAEMA is a weak polybase and the $\mathrm{p} K_{\mathrm{a}}$ of its conjugated acid is about 7.3, ${ }^{38-42}$ the structural difference between PDEAEMA and poly(Fc-DEAE-AM) might result in different $\mathrm{pH}^{-}$ stimulus responsiveness. Therefore, we firstly conducted a titration experiment by adding an $\mathrm{NaOH}$ aqueous solution $(1.0 \mathrm{M})$ dropwise to the acidic solution of the poly(Fc-DEAE-AM) 4a homopolymer, for measuring the relationship between the protonation degree of the DEAE group and the $\mathrm{pH}$ of the aqueous solution. ${ }^{43}$ As shown in Fig. 3A, there are two transition points existing in the titration process (point ' $\mathrm{a}$ ', $\mathrm{pH} \sim$ 4.27 and point ' $\mathrm{b}$ ', $\mathrm{pH} \sim 8.15$ ) according to the changing trends of the $\mathrm{pH}$ value and conductivity. Since the mobility of $\mathrm{H}^{+}\left(\lambda_{\mathrm{H}^{+}}=350 \mathrm{~S} \mathrm{~cm}^{2} \mathrm{~mol}^{-1}\right)$ is much higher than that of $\mathrm{Na}^{+}$ $\left(\lambda_{\mathrm{Na}^{+}}=50.5 \mathrm{~S} \mathrm{~cm}^{2} \mathrm{~mol}^{-1}\right)$, the conductivity of the polymercontaining solution decreased in region 1 due to the decrease of the concentration of $\mathrm{H}^{+}$though the concentration of $\mathrm{Na}^{+}$ increased. In region 2 , the conductivity increased slowly because the initial portion of the $\mathrm{NH}^{+}\left(\mathrm{C}_{2} \mathrm{H}_{5}\right)_{2}$ macro-ions were deprotonated. The rapid ascending of conductivity in region 3 indicated the increase in the concentration of $\mathrm{Na}^{+}$. As a result, region 2 from point ' $a$ ' to point ' $b$ ' corresponded to the deprotonation process of the $\mathrm{NH}^{+}\left(\mathrm{C}_{2} \mathrm{H}_{5}\right)_{2}$ moiety. The $\mathrm{pH}$ value was plotted against the protonation degree $(\alpha)$ to further demonstrate the relationship between the dissociation of the polyelectrolyte and the changing of $\mathrm{pH}$ in the presence of salt (Fig. 3B). The magnitude of $\alpha$ was determined by the moles of titrated polyelectrolyte and the titrant added, where $\alpha$ ranged from 0 at the un-ionized state of the amine group ( $\mathrm{pH} \sim 8.15)$ to 1.0 at the fully protonated state $(\mathrm{pH} \sim 4.27)$. On the other hand, the zeta-potential of the aggregates formed by the poly (FC-DEAE-AM) 4a homopolymer increased from $38.2 \mathrm{mV}$ to $45.4 \mathrm{mV}$ after the $\mathrm{pH}$ was adjusted from 9.0 to 3.0, which indicated that the DEAE group was protonated to the $\mathrm{NH}^{+}\left(\mathrm{C}_{2} \mathrm{H}_{5}\right)_{2}$ group with a positive charge.

Either the immiscibility of one of the blocks in a given solvent or their mutual incompatibility is reported to be the driving force for the self-assembly of the block copolymer. ${ }^{44}$
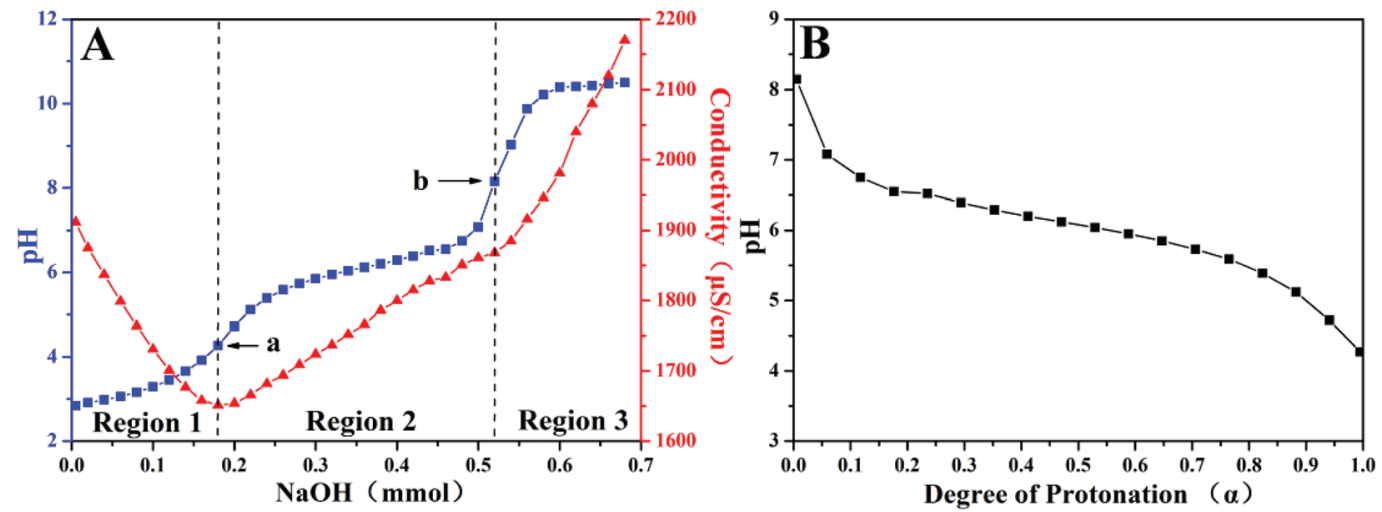

Fig. 3 (A) Titration curves of poly(Fc-DEAE-AM) 4 a homopolymer $\left(2.0 \mathrm{mg} \mathrm{mL}^{-1}\right)$ at $25^{\circ} \mathrm{C}$ in aqueous media with $10 \mathrm{mM} \mathrm{NaCl}$; (B) profile of dependence of protonation on $\mathrm{pH}$. 

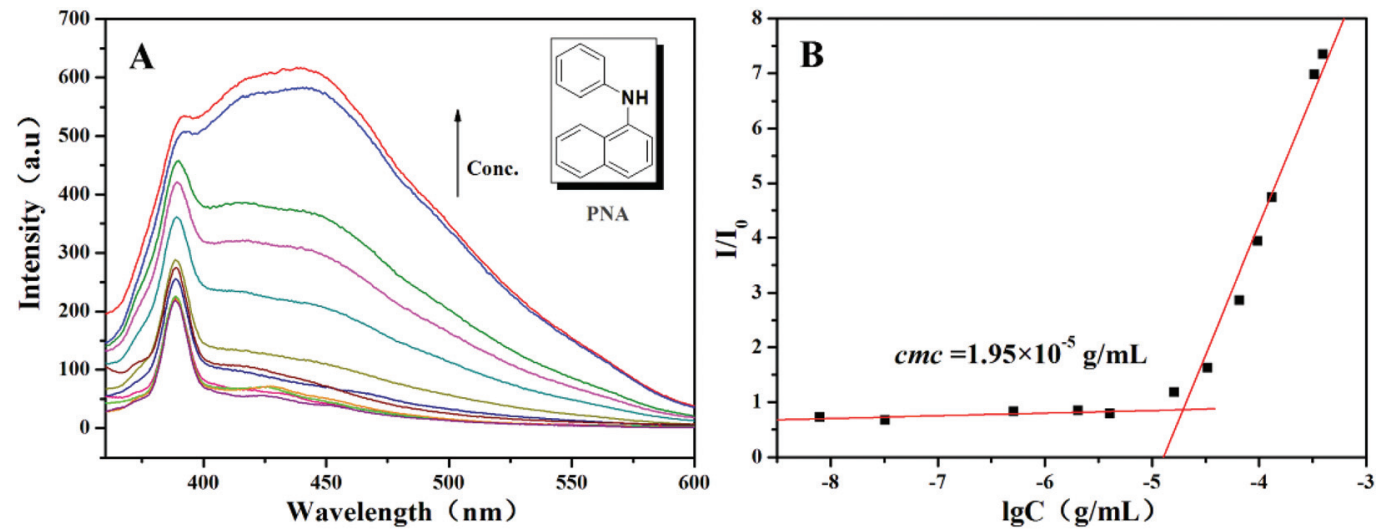

Fig. 4 (A) Fluorescence emission spectra of PNA in aqueous solution of poly(Fc-DEAE-AM) 4 a homopolymer ([PNA] $=2 \times 10^{-6}$ mol $\left.\mathrm{L}^{-1}\right)$; (B) dependence of fluorescence intensity ratio of PNA emission band at $418 \mathrm{~nm}$ on the concentration of poly(Fc-DEAE-AM) $4 a$ homopolymer at $25{ }^{\circ} \mathrm{C}$ in an acidic environment $(\mathrm{pH}=3.0)$.

Unlike the copolymer, the main driving force for the selfassembly of the homopolymer depends on intramolecular phase separation. ${ }^{45,46}$ When the $\mathrm{pH}$ of the solution is decreased to 3.0, the DEAE group would be in the protonation state $\left(\mathrm{DEAE}^{+}\right)$completely while the $\mathrm{Fc}$ in the reduction state is known to be a kind of hydrophobic moiety. As a result, the poly(Fc-DEAE-AM) homopolymer would be endowed with the amphiphilic property in acidic aqueous solution. This characteristic provides an opportunity to investigate self-assembly behavior in aqueous media.

The critical aggregation concentration (CAC) of the poly(FcDEAE-AM) 4a homopolymer in aqueous solution was determined by fluorescence spectroscopy using PNA as the fluorescent probe at three different $\mathrm{pH}$ values $(3.0,7.0$, and 10.0) and a constant temperature of $25{ }^{\circ} \mathrm{C}$. It was reported that the fluorescence intensity of PNA was sensitive to the environment and the polarity of its surroundings, and it could be very easily quenched by polar solvents such as water. ${ }^{47}$ Once the aggregates were formed in aqueous solution, the hydrophobic PNA could be encapsulated into the hydrophobic core so as to dramatically increase the value of $I / I_{0}\left(I\right.$ and $I_{0}$ are the fluorescence intensities of PNA at $418 \mathrm{~nm}$ with and without poly(FcDEAE-AM) 4a homopolymer in the solution, respectively) of its emission spectrum. ${ }^{47}$ The fluorescence intensity of PNA at $\mathrm{pH}$ $=3.0$, at which the amine groups are completely protonated, showed a clear increase when the concentration of homopolymer 4a exceeded a certain value (Fig. 4A). Thus, the CAC of the poly(Fc-DEAE-AM) 4a homopolymer was determined to be the intersection of two straight lines with a value of $1.95 \times 10^{-5}$ $\mathrm{g} \mathrm{mL}^{-1}$ as shown in Fig. 4B. At the same time, the fluorescence emission spectra of PNA in neutral $(\mathrm{pH}=7.0)$ and basic $(\mathrm{pH}=$ 10.0) aqueous solutions of the poly(Fc-DEAE-AM) 4a homopolymer showed no obvious CAC with the increase of concentration of the homopolymer (Fig. S7 $\dagger$ ).

It is well known that the $\mathrm{pH}$ value of saturated $\mathrm{CO}_{2}$ aqueous solution is about 3.9 at ambient temperature and atmosphere pressure due to the chemical equilibrium with weak carbonic acid. ${ }^{48}$ Unlike commonly used acids for adjusting the $\mathrm{pH}$ of solutions, dissolved $\mathrm{CO}_{2}$ gas can be easily removed from the solution by bubbling of inert gas such as $\mathrm{N}_{2}$ or Ar. The titration experiment showed that the protonation of the DEAE moiety also has the expected $\mathrm{pH}$ responsiveness. In order to test if the homopolymer is able to exhibit $\mathrm{CO}_{2}$-responsive behavior in aqueous solution, we monitored the transmittance change of the poly(Fc-DEAE-AM) 4a homopolymer in aqueous solution at $25{ }^{\circ} \mathrm{C}$ by alternating bubbling with $\mathrm{CO}_{2} / \mathrm{N}_{2}$ (Fig. 5). It is found that the solution appears turbid when prepared by bubbling with $\mathrm{N}_{2}$ for $10 \mathrm{~min}$ and then sonication for $10 \mathrm{~min}$ at $25{ }^{\circ} \mathrm{C}$ with transmittance of $0.6 \%$, whereas the solution turns clear immediately with a sharp increase in transmittance from $0.6 \%$ to $97.5 \%$ in $10 \mathrm{~s}$ after the treatment with $\mathrm{CO}_{2}$. Although the solution turns turbid again with the decrease in transmittance from $97.5 \%$ to $0.6 \%$ after the treatment with $\mathrm{N}_{2}$, it takes about $60 \mathrm{~min}$ for the decrease of transmittance from $97.5 \%$ to $0.6 \%$. We speculate that the difference in response time might result from a higher affinity of the DEAE moieties toward $\mathrm{CO}_{2}$,

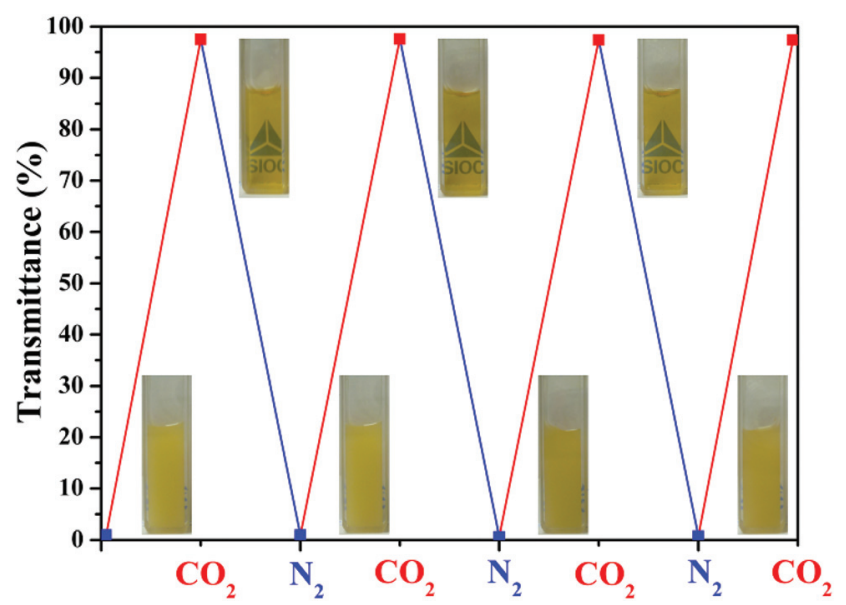

Fig. 5 Optical appearances and transmittance changes of aqueous solution of poly(Fc-DEAE-AM) 4a homopolymer $\left(2.0 \mathrm{mg} \mathrm{mL}^{-1}\right)$ with $\mathrm{CO}_{2} / \mathrm{N}_{2}$ gas triggers. 
in comparison with $\mathrm{N}_{2}$. In addition, we found that the zetapotential increased from $38.2 \mathrm{mV}$ to $45.5 \mathrm{mV}$ after the treatment with $\mathrm{CO}_{2}$. The increase in zeta-potential also indicated the protonation of the tertiary amine group. Subsequently, after passing $\mathrm{N}_{2}$ through the solution to remove $\mathrm{CO}_{2}$, a sharp drop in transmittance was observed due to the deprotonation of the tertiary amine group. Repeatable cycles under an alternating $\mathrm{CO}_{2} / \mathrm{N}_{2}$ stimulation as shown in Fig. 5 indicated the gas-responsive reversibility of the poly(Fc-DEAE-AM) 4a homopolymer.

\section{Redox-responsive behavior of poly(Fc-DEAE-AM) in aqueous media}

The inter-conversion between reduced and oxidized forms can lead to the transition from hydrophobicity to hydrophilicity of the hydrophobic part of Fc-containing polymers. ${ }^{12-23}$ We then examined the effect of oxidation on the self-assembly behavior of a poly(Fc-DEAE-AM) 4a homopolymer under both basic and acidic conditions (Fig. 6A). Upon treating the solution with an equivalent amount of $\mathrm{FeCl}_{3}$ oxidant, the transparency of the basic solution $(\mathrm{pH}=9.0)$ was improved immediately $(<10 \mathrm{~s})$, accompanied by a distinct color change from orange to green, which is similar to the observations in a previous report. ${ }^{12}$ The change in color of the solution after treatment with $\mathrm{FeCl}_{3}$ might result from the formation of $\mathrm{Fe}^{2+}$ by the oxidation of $\mathrm{Fc}$ to $\mathrm{Fc}^{+}$with $\mathrm{Fe}^{3+}$ on the basis of a previous report. ${ }^{12}$ After the addition of vitamin $\mathrm{C}(\mathrm{VC})$, the solution turned dark yellow immediately $(<10 \mathrm{~s})$ along with the formation of precipitate because all DEAE groups were not protonated in a basic environment according to the dependence of protonation on $\mathrm{pH}$ (Fig. 3B). One can notice that the color of the solution (dark yellow) after treatment with $\mathrm{FeCl}_{3}$ and $\mathrm{VC}$ is different from that of the original solution (yellow), though all of the $\mathrm{Fc}^{+}$should be reduced to $\mathrm{Fc}$ after the treatment with $\mathrm{VC}$ according to previous reports. ${ }^{12-23}$ We speculate that the presence of additional $\mathrm{Fe}^{3+}$ and $\mathrm{Fe}^{2+}$ after the addition of $\mathrm{FeCl}_{3}$ and VC might lead to the difference between the color of the final solution and that of the original solution. Similarly, the color of the transparent acidic solution $(\mathrm{pH}=3.0)$ also changed from orange to green upon the addition of $\mathrm{FeCl}_{3}$, and turned dark yellow with the addition of VC. The zeta potential of the aqueous solution of the poly(Fc-DEAE-AM) 4a homopolymer greatly increased from $38.2 \mathrm{mV}$ to $49.7 \mathrm{mV}$ after the $\mathrm{FeCl}_{3}$ was injected, which demonstrated that the Fc group was oxidized to $\mathrm{Fc}^{+}$. After the addition of $\mathrm{VC}$, the zeta potential decreased to $39.5 \mathrm{mV}$, indicative of the reduction of $\mathrm{Fc}^{+}$to $\mathrm{Fc}$ again. However, a stable colloidal solution was formed without the formation of any precipitate due to the presence of hydrophilic $\mathrm{NH}^{+}\left(\mathrm{C}_{2} \mathrm{H}_{5}\right)_{2}$ moieties at $\mathrm{pH}=3.0$. To further probe the reversible redox behavior of the poly(Fc-DEAE-AM) 4a homopolymer, UV/vis spectra were recorded in acidic solution as shown in Fig. 6B. The original homopolymer gave rise to an absorbance at $446 \mathrm{~nm}$, and upon the addition of $\mathrm{FeCl}_{3}$ (oxidant), the signal at $446 \mathrm{~nm}$ decreased while a new signal originating from the formation of $\mathrm{Fc}^{+}$state was observed at $636 \mathrm{~nm}$. The signal at $446 \mathrm{~nm}$ re-appeared after the reduction of the ferrocenium moiety by adding VC (reductant), which proved that this redox process is reversible.

The TEM image (Fig. 7A) showed that initial spherical aggregates with hydrophobic Fc domains and hydrophilic protonated DEAE segments were formed when the $\mathrm{pH}$ of the solution was 3.0 with an average diameter of $219 \mathrm{~nm}$ measured by DLS (Fig. 8A). As an equivalent amount of oxidant $\left(\mathrm{FeCl}_{3}\right)$ was added to the solution $(1.1 \mathrm{mM})$, the size of aggregates in the solution decreased significantly to $160 \mathrm{~nm}$ (Fig. 7B), which was consistent with the result of DLS (162 nm) in Fig. 8A. It is worth noting that vesicles were formed after the addition of $\mathrm{FeCl}_{3}$ and one can clearly notice a dark rim in Fig. 7B, which was attributed to the membrane of the vesicle. After an equivalent amount of reductant (VC) was added (1.1 $\mathrm{mM})$, the aggregates transformed into typical spheres with a size of $190 \mathrm{~nm}$ (Fig. 7C and 8A). One might argue that the addition of $\mathrm{FeCl}_{3}$ also led to the increase of the concentration of salt, which could affect the self-assembly behavior of amphiphilic
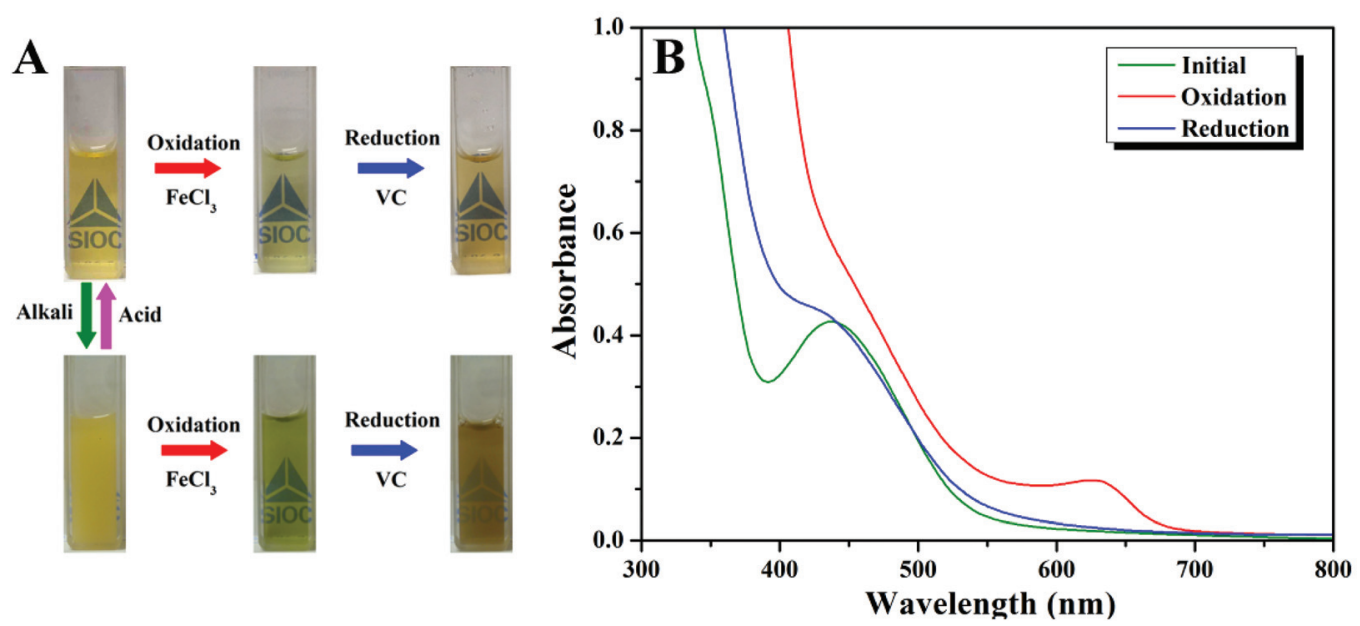

Fig. 6 (A) Photographs of aqueous solution of poly(Fc-DEAE-AM) 4a homopolymer after treating with multi-stimuli; (B) UV/vis absorption spectra of acidic aqueous solution of poly(Fc-DEAE-AM) $4 a$ homopolymer $\left(2.0 \mathrm{mg} \mathrm{mL}^{-1}\right)$ before and after the treatment of redox agent. 


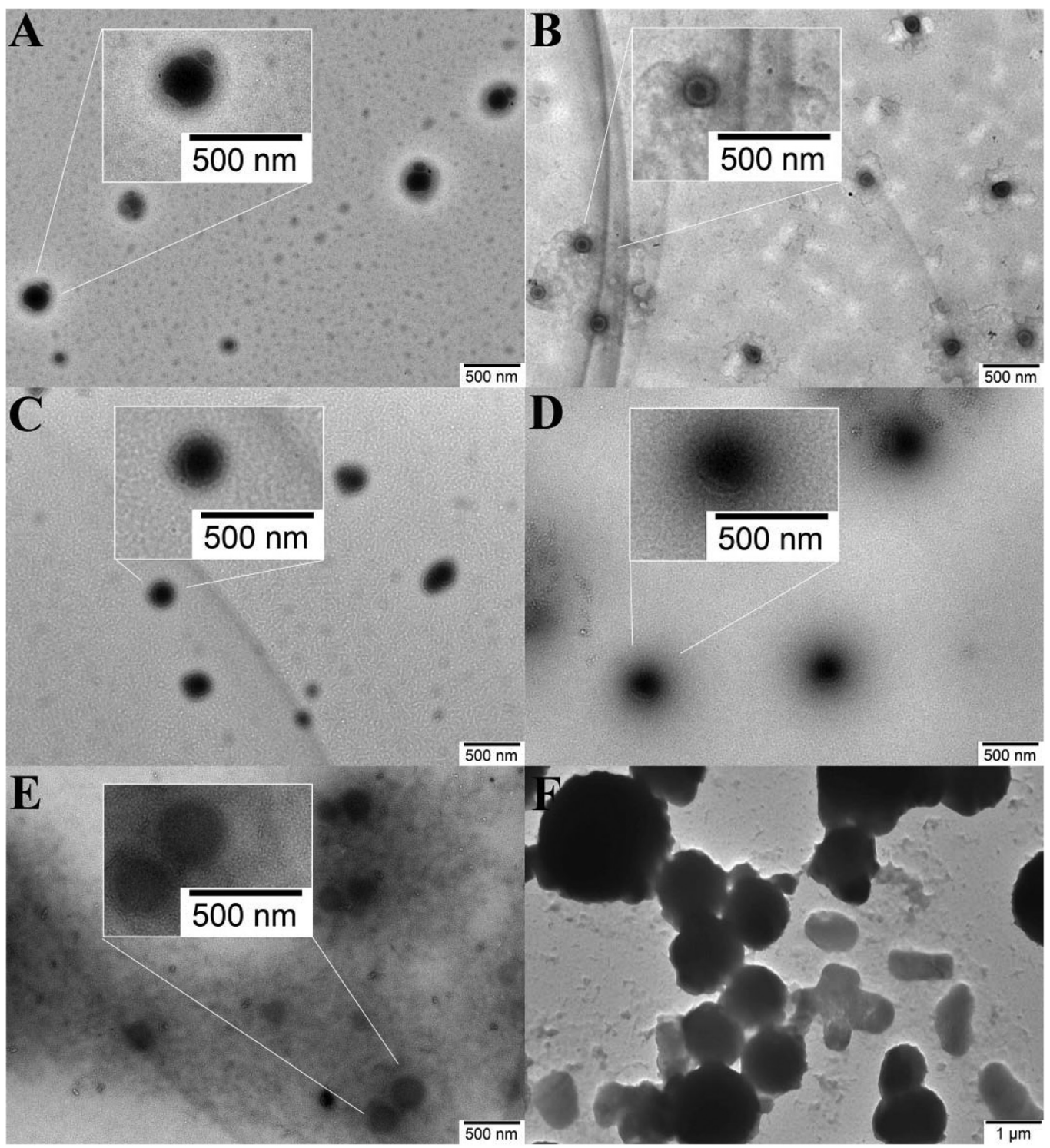

Fig. 7 TEM images of aggregated formed by poly(Fc-DEAE-AM) 4 a homopolymer at $25^{\circ} \mathrm{C}$ in an acidic environment $(0.5 \mathrm{mg} \mathrm{mL}-1$ and $\mathrm{pH}=3.0)$ : before (A) and after (B) oxidation by $\mathrm{FeCl}_{3}$; reduction (C) by vitamin $\mathrm{C}$; in $1.7 \mathrm{mM}$ (D), $17 \mathrm{mM}(\mathrm{E})$, and $170 \mathrm{mM}$ (F) $\mathrm{NaCl}$ aqueous solution.
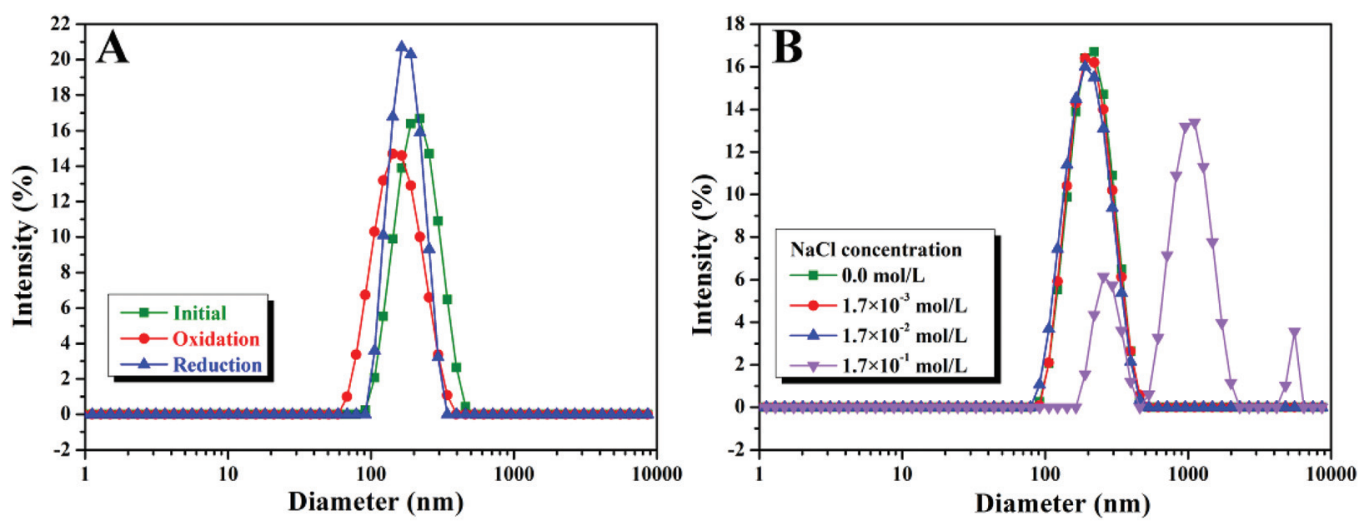

Fig. 8 Size distributions of poly(Fc-DEAE-AM) 4 a homopolymer at $25^{\circ} \mathrm{C}$ in an acidic environment $(\mathrm{pH}=3.0)$ : aggregates $(\mathrm{A})$ before and after treatment of redox agent; (B) at different concentrations of $\mathrm{NaCl}$. 
block copolymer and micellar morphologies according to previous reports. ${ }^{49-51}$ In order to make this issue clear, we added different amounts of $\mathrm{NaCl}$ into the aqueous solution of the poly(Fc-DEAE-AM) $\mathbf{4 a}$ homopolymer instead of $\mathrm{FeCl}_{3}$. Noticeable spherical aggregates were observed from the TEM and DLS analysis as the concentration of $\mathrm{NaCl}$ was 1.7 and $17 \mathrm{mM}$, respectively, while large aggregates were formed as the concentration of $\mathrm{NaCl}$ increased to $170 \mathrm{mM}$. These observations indicated that the formation of vesicles after the addition of $\mathrm{FeCl}_{3}$ predominantly resulted from the formation of $\mathrm{Fc}^{+}$, which changed the hydrophilic-hydrophobic balance of the poly(Fc-DEAE-AM) homopolymer, although we cannot completely exclude the marginal effect of increasing the ion concentration.

\section{Conclusion}

In summary, we synthesized a new type of acrylamide monomer by combining a $\mathrm{pH} / \mathrm{CO}_{2}$-responsive DEAE moiety, a redox-responsive Fc group, and a polymerizable double bond into a single monomer via aza-Michael addition and amidation reaction. A well-defined triple-stimuli-responsive poly(FcDEAE-AM) homopolymer was then obtained by RAFT polymerization. The aggregation behavior of the homopolymer in aqueous media was investigated by the combination of a fluorescent probe, UV/vis transmittance, and zeta potential. It is found that the poly(Fc-DEAE-AM) homopolymer shows $\mathrm{pH} /$ $\mathrm{CO}_{2}$ and redox responsiveness as demonstrated by the phase transition in aqueous solution. In addition, TEM and DLS measurements indicate that such a homopolymer could form typical spherical particles in acidic aqueous solution, and a redox agent could result in changes in the size and morphology of the aggregates. Compared with the multi-stimuli responsive Fc-containing polymers reported before, ${ }^{20,22,23}$ we offer a new and efficient method for obtaining triple-stimuliresponsive Fc-containing homopolymers. The novel FcDEAE-AM monomer broadens the field of Fc-containing monomers and polymers toward polyacrylamide. The end CTA group in the poly(Fc-DEAE-AM) homopolymer might provide the opportunity for post-modification by introducing additional functional chains, which further broadens the potential application of these kinds of polymers.

\section{Acknowledgements}

The authors are grateful for the financial support from the National Basic Research Program of China (2015CB931900), National Natural Science Foundation of China (21474127), Strategic Priority Research Program of the Chinese Academy of Sciences (XDB20000000), Youth Innovation Promotion Association of Chinese Academy of Sciences (2016233), and Shanghai Scientific and Technological Innovation Project (16JC1402500, 14520720100, and 16520710300).

\section{References}

1 T. Thambi, J. H. Park and D. S. Lee, Stimuli-Responsive Polymersomes for Cancer Therapy, Biomater. Sci., 2016, 4, 55-69.

2 M. Wei, Y. Gao, X. Li and M. J. Serpe, Stimuli-Responsive Polymers and Their Applications, Polym. Chem., 2017, 8, 127-143.

3 G. Kocak, C. Tuncer and V. Butun, pH-Responsive Polymers, Polym. Chem., 2017, 8, 144-176.

4 E. Cabane, V. Malinova, S. Menon, C. G. Palivan and W. Meier, Photoresponsive Polymersomes as Smart, Triggerable Nanocarriers, Soft Matter, 2011, 7, 9167-9176.

5 A. Topete, S. Barbosa and P. Taboada, Intelligent Micellar Polymeric Nanocarriers for Therapeutics and Diagnosis, J. Appl. Polym. Sci., 2015, 132, 42650.

6 A. C. Hunter and S. M. Moghimi, Smart Polymers in Drug Delivery: A Biological Perspective, Polym. Chem., 2017, 8, 41-51.

7 J. Zhuang, M. R. Gordon, J. Ventura, L. Li and S. Thayumanavan, Multi-Stimuli Responsive Macromolecules and Their Assemblies, Chem. Soc. Rev., 2013, 42, 7421-7435.

8 S. Guragain, B. P. Bastakoti, V. Malgras, K. Nakashima and Y. Yamauchi, Multi- Stimuli-Responsive Polymeric Materials, Chem. - Eur. J., 2015, 21, 13164-13174.

9 A. Napoli, M. J. Boerakker, N. Tirelli, R. J. M. Nolte, N. A. J. M. Sommerdijk and J. A. Hubbell, Glucose-oxidase Based Self-Destructing Polymeric Vesicles, Langmuir, 2004, 20, 3487.

10 N. Ma, Y. Li, H. P. Xu, Z. Wang and X. Zhang, Dual Redox Responsive Assemblies Formed from Diselenide Block Copolymers, J. Am. Chem. Soc., 2010, 132, 442-443.

11 H. Ren, Y. Wu, N. Ma, H. Xu and X. Zhang, Side-chain Selenium-Containing Amphiphilic Block Copolymers: Redox-Controlled Self-Assembly and Disassembly, Soft Matter, 2012, 8, 1460-1466.

12 B. Adhikari, R. Afrasiabi and H.-B. Kraatz, FerroceneTryptophan Conjugate: An Example of a Redox-Controlled Reversible Supramolecular Nanofiber Network, Organometallics, 2013, 32, 5899-5905.

13 X. Chang, R. Dong, B. Ren, Z. Cheng, J. Peng and Z. Tong, Novel Ferrocenyl-Terminated Linear-Dendritic Amphiphilic Block Copolymers: Synthesis, Redox-Controlled Reversible Self-Assembly, and Oxidation-Controlled Release, Langmuir, 2014, 30, 8707-8716.

14 P. Shi, Y. Qu, C. Liu, H. Khan, P. Sun and W. Q. Zhang, Redox-Responsive Multicompartment Vesicles of Ferrocene-Containing Triblock Terpolymer Exhibiting OnOff Switchable Pores, ACS Macro Lett., 2016, 5, 88-93.

15 Q. Yan, J. Y. Yuan, Z. Cai, Y. Xin, Y. Kang and J. Y. Yin, Voltage-Responsive Vesicles Based on Orthogonal Assembly of Two Homopolymers, J. Am. Chem. Soc., 2010, 132, 92689270.

16 Q. Yan, A. Feng, H. Zhang, Y. Yin and J. Y. Yuan, RedoxSwitchable Supramolecular Polymers for Responsive Self- 
Healing Nanofibers in Water, Polym. Chem., 2013, 4, 12161220.

17 L. Peng, H. Zhang, A. Feng, M. Huo, Z. Wang, J. Hu, W. Gao and J. Y. Yuan, Electrochemical Redox Responsive Supramolecular Self-Healing Hydrogels Based on HostGuest Interaction, Polym. Chem., 2015, 6, 3652-3659.

18 X. Chang, Z. Cheng, B. Ren, R. Dong, J. Peng, S. Fu and Z. Tong, Voltage-Responsive Reversible Self-Assembly and Controlled Drug Release of Ferrocene-Containing Polymeric Superamphiphiles, Soft Matter, 2015, 11, 7494-7501.

19 R. L. N. Hailes, A. M. Oliver, J. Gwyther, G. R. Whittell and I. Manners, Polyferrocenylsilanes: Synthesis, Properties, and Applications, Chem. Soc. Rev., 2016, 45, 5358-5407.

20 B. V. K. J. Schmidt, J. Elbert, C. Barner-Kowollik and M. Gallei, Individually Addressable Thermo- and RedoxResponsive Block Copolymers by Combining Anionic Polymerization and RAFT Protocols, Macromol. Rapid Commun., 2014, 35, 708-714.

21 A. Alkan and F. R. Wurm, Water-Soluble MetalloceneContaining Polymers, Macromol. Rapid Commun., 2016, 37, 1482-1493.

22 C. Tonhauser, A. Alkan, M. Schömer, C. Dingels, S. Ritz, V. Mailänder, H. Frey and F. R. Wurm, Ferrocenyl Glycidyl Ether: A Versatile Ferrocene Monomer for Copolymerization with Ethylene Oxide to Water-Soluble, Thermoresponsive Copolymers, Macromolecules, 2013, 46, 647-655.

23 A. Alkan, C. Steinmetz, K. Landfester and F. R. Wurm, Triple-Stimuli-Responsive Ferrocene-Containing PEGs in Water and on the Surface, ACS Appl. Mater. Interfaces, 2015, 7, 26137-26144.

24 X. Jiang, C. Feng, G. L. Lu and X. Y. Huang, Thermoresponsive Homopolymer Tunable by $\mathrm{pH}$ and $\mathrm{CO}_{2}$, ACS Macro Lett., 2014, 3, 1121-1125.

25 X. Jiang, C. Feng, G. L. Lu and X. Y. Huang, Synthesis of Temperature and $\mathrm{pH} / \mathrm{CO}_{2}$ Responsive Homopolymer Bearing Oligo(ethylene glycol) Unit and $N, N$-diethylamino Ethyl Group and Its Solution Property, Polymer, 2015, 64, 268-276.

26 X. Jiang, C. Feng, G. L. Lu and X. Y. Huang, Oxygen and Carbon Dioxide Dual Gas-Responsive Homopolymers and Diblock Copolymers Synthesized via RAFT Polymerization, Polym. Chem., 2017, 8, 1163-1176.

27 P. G. Jessop, L. Kozycz, Z. G. Rahami, D. Schoenmakers, A. R. Boyd, D. Wechsler and A. M. Holland, Tertiary Amine Solvents Having Switchable Hydrophilicity, Green Chem., 2011, 13, 619-623.

28 D. Han, X. Tong, O. Boissiere and Y. Zhao, General Strategy for Making $\mathrm{CO}_{2}$-Switchable Polymers, ACS Macro Lett., 2012, 1, 57-61.

29 D. Han, O. Boissiere, S. Kumar, X. Tong, L. Tremblay and Y. Zhao, Two-Way $\mathrm{CO}_{2}$-Switchable Triblock Copolymer Hydrogels, Macromolecules, 2012, 45, 7440-7445.

30 B. Yan, D. Han, O. Boissiere, P. Ayotte and Y. Zhao, Manipulation of Block Copolymer Vesicles Using $\mathrm{CO}_{2}$ : Dissociation or "Breathing", Soft Matter, 2013, 9, 20112016.
31 Q. Yan and Y. Zhao, $\mathrm{CO}_{2}$-Stimulated Diversiform Deformations of Polymer Assemblies, J. Am. Chem. Soc., 2013, 135, 16300-16303.

32 K. Ponnusamy, R. P. Babu and R. Dhamodharan, Synthesis of Block and Graft Copolymers of Styrene by RAFT Polymerization, Using Dodecyl-Based Trithiocarbonates as Initiators and Chain Transfer Agents, J. Polym. Sci., Part A: Polym. Chem., 2013, 51, 1066-1078.

33 J. Chiefari, Y. K. Chong, F. Ercole, J. Krstina, J. Jeffery, P. T. Le Tam, R. Mayadunne, G. F. Meijs, C. L. Moad, G. Moad, E. Rizzardo and S. H. Thang, Living Free-Radical Polymerization by Reversible Addition-Fragmentation Chain Transfer:The RAFT Process, Macromolecules, 1998, 31, 5559-5562.

34 C. L. McCormick and A. B. Lowe, Aqueous RAFT Polymerization: Recent Developments in Synthesis of Functional Water-Soluble (Co)polymers with Controlled Structures, Acc. Chem. Res., 2004, 37, 312-325.

35 G. Moad, E. Rizzardo and S. H. Thang, Living Radical Polymerization by the RAFT Process, Aust. J. Chem., 2005, 58, 379-410.

36 G. Moad, E. Rizzardo and S. H. Thang, Living Radical Polymerization by the RAFT Process-A First Update, Aust. J. Chem., 2006, 59, 669-692.

37 G. Moad, E. Rizzardo and S. H. Thang, Living Radical Polymerization by the RAFT Process-A Second Update, Aust. J. Chem., 2009, 62, 1402-1472.

38 A. S. Lee, A. P. Gast, V. Butun and S. P. Armes, Characterizing the Structure of $\mathrm{pH}$ Dependent Polyelectrolyte Block Copolymer Micelles, Macromolecules, 1999, 32, 4302-4310.

39 S. Y. Liu, N. C. Billingham and S. P. Armes, A Schizophrenic Water-Soluble Diblock Copolymer, Angew. Chem., Int. Ed., 2001, 40, 2328-2331.

40 E. J. Lobb, I. Ma, N. C. Billingham and S. P. Armes, Facile Synthesis of Well- Defined, Biocompatible Phosphorylcholine-Based Methacrylate Copolymers via Atom Transfer Radical Polymerization at $20{ }^{\circ} \mathrm{C}, \mathrm{J}$. Am. Chem. Soc., 2001, 123, 7913-7914.

41 H. Zhang, P. Ni, J. He and C. Liu, Novel Fluoroalkyl EndCapped Amphiphilic Diblock Copolymers with $\mathrm{pH} /$ Temperature Response and Self-Assembly Behavior, Langmuir, 2008, 24, 4647-4654.

42 X. Chen, D. P. Randall, C. Perruchot, J. F. Watts, T. E. Patten, T. Werne and S. P. Armes, Synthesis and Aqueous Solution Properties of Polyelectrolyte-Grafted Silica Particles Prepared by Surface-Initiated Atom Transfer Radical Polymerization, J. Colloid Interface Sci., 2003, 257, 56-64.

43 E. He, P. Ravi and K. C. Tam, Synthesis and Self-Assembly Behavior of Four-Arm Poly(ethylene oxide)- $b$-poly(2-(diethylamino)ethyl methacrylate) Star Block Copolymer in Salt Solutions, Langmuir, 2007, 23, 2382-2388.

44 T. S. Kale, A. Klaikherd, B. Popere and S. Thayumanavan, Supramolecular Assemblies of Amphiphilic Homopolymers, Langmuir, 2009, 25, 9660-9670. 
45 S. Basu, D. R. Vutukuri, S. Shyamroy, B. S. Sandanaraj and S. Thayumanavan, Invertible Amphiphilic Homopolymers, J. Am. Chem. Soc., 2004, 126, 9890-9891.

46 Y. Zhu, L. Liu and J. Z. Du, Probing into Homopolymer Self-Assembly: How Does Hydrogen Bonding Influence Morphology, Macromolecules, 2013, 46, 194-203.

47 P. S. Xu, H. D. Tang, S. Y. Li, J. Ren, E. Van Kirk, W. J. Murdoch, M. Radosz and Y. Q. Shen, Enhanced Stability of Core-Surface Cross-Linked Micelles Fabricated from Amphiphilic Brush Copolymers, Biomacromolecules, 2004, 5, 1736-1744.

48 H. Liu, S. Lin, Y. Feng and P. Theato, $\mathrm{CO}_{2}$-Responsive Polymer Materials, Polym. Chem., 2017, 8, 12-23.
49 R. J. Barlow, S. Zimmerman, K. Khoucaz and A. Eisenberg, Phase Separation of Micellar Solutions at Extreme Dilution: A Study of Polystyrene-6-poly(sodium Acrylate) Micelles in Aqueous NaCl Solutions, J. Polym. Sci., Part B: Polym. Phys., 1996, 34, 1197-1212.

50 L. Zhang and A. Eisenberg, Morphogenic Effect of Added Ions on Crew-Cut Aggregates of Polystyrene- $b$-poly(acrylic acid) Block Copolymers in Solutions, Macromolecules, 1996, 29, 8805-8815.

51 S. V. Solomatin, T. K. Bronich, T. W. Bargar, A. Eisenberg, V. A. Kabanov and A. V. Kabanov, Environmentally Responsive Nanoparticles from Block Ionomer Complexes: Effects of $\mathrm{pH}$ and Ionic Strength, Langmuir, 2003, 19, 8069-8076. 